\title{
Humanidades y formación contable: una relación necesaria para otear una reorientación de la profesión contable*
}

doi:10.11144/Javeriana.cc16-40.hfcr

\section{William Rojas-Rojas}

Doctor (c) en ciencias de gestión, Conservatoire National des Arts et Métiers, CNAM. DEA en desarrollo de recursos humanos, CNAM. MSc en organizaciones, contador público y licenciado en filosofía, Universidad del Valle. Profesor tiempo completo, programa de contaduría pública, Universidad del Valle. Integrante del grupo de investigación Nuevo Pensamiento Administrativo. Miembro Académico del Centro Colombiano de Investigaciones Contables, C-Cinco.

Correo electrónico: william.rojas@correounivalle.edu.co

\section{Gregorio A. Giraldo-Garcés}

Magíster en ciencias de la organización y contador público, Universidad del Valle. Profesor tiempo completo, programa de contaduría pública, Universidad del Valle. Integrante del grupo de investigación Nuevo Pensamiento Administrativo. Miembro Académico del Centro Colombiano de Investigaciones Contables, C-Cinco. Correo electrónico: gregorio.giraldo@correounivalle.edu.co

\footnotetext{
* Este artículo es producto de las discusiones académicas de la línea de investigación Modernidad y modernización desde la perspectiva del saber contable, del Grupo Nuevo Pensamiento Administrativo de la Universidad del Valle. En su primera versión se presentó para ser discutido en el III Encuentro de Profesores de Contaduría Pública en Cali, 2013. Con base en la retroalimentación y el debate, se precisaron nuevos argumentos y conceptos que dieron un giro a la propuesta del escrito.
} 
Resumen La educación contable se puede concebir como un proceso de transformación que incide no solo en la vida de quienes deciden asumir la contabilidad como profesión, sino que su ejercicio repercute directamente en el desarrollo de las dinámicas organizacionales y sociales. Las instituciones de educación superior que cuentan con este programa tienen la posibilidad de orientar la formación de contadores públicos de manera integral y crítica, siempre y cuando los actores que la viabilizan conjuren una nueva forma de abordar el hacer y las prácticas pedagógicas. En este sentido, el propósito de este texto es reflexionar en voz alta acerca de los caminos que se han venido desarrollando para transformar las prácticas contables y los procesos pedagógicos que sirven para impulsar la aparición de contadores capaces de repotenciar el telos de la profesión. Realmente se quiere invitar a pensar si se han dado cambios en la forma en que los miembros de la comunidad contable conciben la importancia de las humanidades (ciencias sociales y humanas) en el proceso de formación contable. En este horizonte de reflexión es pertinente preguntarse ¿cuál es la dimensión que se le da al componente de las humanidades en nuestro currículo? Para formular algunos elementos de análisis, se considera importante invitar a estudiar los desarrollos que se han obtenido con el ingreso de las humanidades a los currículos.

Palabras clave Educación; formación contable; contabilidad; universidad; capitalismo; humanidades.

Códigos JEL M41; M49

Humanities and Accounting Training: A Necessary Relationship to Explore a Reorientation of the Accounting Profession

\footnotetext{
Abstract Education on accounting may be interpreted as a transformation process that has an influence not only on the lives of those who decide to undertake accounting as a career, but also has direct repercussions in corporate and
}

social dynamics. Higher education institutions that offer this major have the possibility to guide the education for future public accountants in an integral and critical way, as long as the actors that make it possible plot together a new way to address their duty and pedagogical practices. In this way, the purpose of this text is to reflect out loud about the ways being developed to transform accounting practices, and the pedagogical processes that work towards boosting the appearance of accountants able to give new power to the telos of the profession. We actually want to lead to thinking whether there have been changes in the form in which the members of the accounting community perceive the importance of humanities (social and human sciences) in the accounting education process. In this reflection scope it is appropriate to ask, what is the dimension given to the humanities component in our curriculum? In order to formulate certain analysis elements we consider important making an invitation for the study of the developments obtained with the entrance of humanities to curricula.

Keywords Education; accounting education; accounting; university; capitalism; humanities.

\section{Humanidades e formação contábil: um relacionamento necessário para enxergar uma reorientação da profissão contábil}

Resumo O ensino contábil pode-se conceber como processo de transformação que incide não apenas na vida de quem decide assumir a contabilidade como profissão, senão que seu exercício repercute direitinho no desenvolvimento das dinâmicas organizacionais e sociais. As instituições de ensino superior que contam com este programa têm a possibilidade de orientar a formação de contadores públicos de maneira integral e crítica, sempre que os atores que a viabilizam conjurar una nova forma de abordar o fazer e as práticas pedagógicas. Neste sentido, o propósito deste texto é refletir em voz alta sobre os caminhos que 
se venceram desenvolvendo para transformar as práticas contábeis e os processos pedagógicos que servem para impulsionar o aparecimento de contadores capazes de repotenciar o telos da profissão. Realmente deseja-se convidar a pensar se tem havido mudanças na forma em que os membros da comunidade contábil concebem a importância das humanidades (ciências sociais e humanas) no processo de formação contábil. Neste horizonte de reflexão é pertinente se perguntar qual a dimensão que se dá para o componente das humanidades no nosso currículo? Para formular alguns elementos de análise, considera-se importante convidar a estudar os desenvolvimentos que se alcançaram com a entrada das humanidades nos currículos.

Palavras-chave Ensino; formação contábil; contabilidade; universidade; capitalismo; humanidades.

\section{Introducción}

Gran parte de los estudiosos de la contabilidad ha elaborado críticas desde diversos ángulos, frente a un proyecto de profesionalización que cree a ciegas en los consensos de los órganos reguladores de la profesión y sus pronunciamientos sobre el porqué de la emergencia de normas contables, muchas de las cuales no favorecen ni se atemperan realmente con los resultados de la investigación en este campo en Colombia. El debate que se deriva de posiciones encontradas entre quienes defienden la adopción o convergencia de normas internacionales de contabilidad y quienes se oponen, está aún por resolverse. ¿Cuáles son los abismos entre estas dos posturas? Es necesario promover una investigación rigurosa que permita identificar cómo los contadores colombianos han tejido sus problematizaciones en términos de las humanidades y cuál ha sido el impacto de su trabajo.
Este escrito invita a abordar la perspectiva vinculante entre la contaduría pública, como proceso formativo, con la riqueza del saber de las humanidades, a otear cómo la investigación contable utiliza los marcos referenciales de las ciencias humanas, y cómo este saber está impactando la docencia y por supuesto, la administración curricular de los programas de contaduría pública. La reflexión académica que se ha venido desarrollando en los últimos 10 años aproximadamente, se ha ocupado de los motivos, consecuencias, impactos, influencias y la forma de operar que se derivan de la educación contable instrumentalista; y aun así, poco parece preocupar la fundamentación conceptual y crítica de los contenidos que finalmente se enseña a los estudiantes (Ospina, 2006; Rojas, 2009; Rueda, Pinzón \& Patiño, 2013).

En un programa de estudio como la contaduría pública, la fundamentación humanista se considera esencial, ya por su razón de ser, ya por sus efectos en el desarrollo de la sociedad. En ese sentido, urge un llamado de atención a los investigadores y a la comunidad académica en general sobre la importancia de mantener alerta la conexión interdisciplinaria con las ciencias sociales y humanas como la historia, la filosofía, la sociología, la antropología, la psicología, el trabajo social, la literatura y la pedagogía, entre otras.

Al tema de la formación se le otorgan una valoración y un significado especial, entendidos como el espacio donde la persona se "da forma" en sentido autónomo y voluntario; forma a su pensamiento, a su ética, a su acción, a su praxis (Quiceno, 2001, pp. 85-87). Este aspecto, traído al campo contable, obliga a revisar los li- 
neamientos que siguen los procesos educativos universitarios en contaduría, porque si bien estos se fundamentan en planes y proyectos que ofrecen una variedad de perfiles y objetivos, no siempre promueven una formación contable en la que el componente humanístico tenga una verdadera aplicabilidad.

El interés de este escrito es promover la reflexión y el pensamiento alrededor de la formación de contadores públicos, con el convencimiento de que las humanidades tienen el potencial para fortalecer el sentido y la perspectiva social tanto de la profesión como del saber contable. Es de suma importancia que los contadores comprendan la trascendencia de sus actos en el ejercicio de su profesión y por medio de estos, puedan contribuir a la reivindicación del ser humano. Jesse F. Dillard (1991, p. 22) prevé la práctica contable como aquella que proporciona los medios para resolver los conflictos sociales, al valorar los términos de intercambio entre grupos sociales, y arbitrar, evaluar y adjudicar las opciones sociales. Con el fin de lograr esto, la definición de una transacción económica se amplía a la "transferencia de una capacidad para afectar el bienestar humano".

Como aspecto metodológico, es pertinente mencionar que se ha recurrido a una perspectiva analítica, tomando como objeto de este análisis el proceso de educación contable caracterizado en Colombia por diversos autores como John Cardona-Arteaga y Miguel Ángel Zapata-Monsalve (2006); Mauricio GómezVillegas (2007); Édgar Gracia (1996, 2000, 2002); Guillermo León Martínez-Pino (2002, 2008); Olver Quijano-Valencia (2002); William Rojas-Rojas (2002); Gabriel Rueda-Delgado,
Jorge Emiro Pinzón-Pinto y Ruth Alejandra Patiño-Jacinto (2013). Con base en estos planteamientos, se propone una reflexión desde los argumentos de Fernando Cruz-Kronfly (2012); Jesús Martín-Barbero (2002) y Edward Said (2006), que se vincula con el papel fundamental de las humanidades en la enseñanza y el ejercicio profesional de la contaduría pública.

\section{Por una estructuración filosófico-humanista en la formación contable}

La convicción de que los currículos y las prácticas pedagógicas de la contaduría pública deben estructurarse filosóficamente para promover una formación integral de los futuros contadores públicos, gana cada vez más adeptos entre los pensadores de la educación contable. De ahí que se pregunte si en Colombia se ha pensado con "claridad" cómo extender y fortalecer esta formación. Se insiste en la necesidad de saber ¿cuál es el rol de las humanidades en un programa que, además de formar un profesional integral, se traza como objetivo prepararlo para el mercado de trabajo?

Todo programa académico demanda un examen permanente por medio del cual se explique y evalúe cómo la formación profesional que lo sustenta, contribuye al fortalecimiento de la democracia y el bienestar general de la sociedad. Como ente autónomo y antes de hacer eco a una lógica económica imperante, la universidad debe pensar la estructura, los métodos, y las perspectivas filosóficas y pedagógicas que sustentan su misión universitaria. La piedra angular de todo proyecto educativo de corte hu- 
manista da relevancia al respeto de la dignidad humana y al cuidado de la vida, y esto se extiende obviamente al quehacer contable. Asimismo, es tarea prioritaria romper las fronteras de un dominio discursivo en contaduría, el cual se encuentra embebido en la funcionalidad propia de la racionalidad instrumental, eje del quehacer y la productividad de las empresas en las últimas décadas. En este sentido, Edward C. Arrington y Jere R. Francis (1993, p. 113) sostienen que:

\footnotetext{
Para acercarse a la contabilidad como una práctica discursiva concebida en términos generales, esta debe ser liberada de la identificación con un lenguaje en particular (por ejemplo, el cálculo de doble entrada), ya que esa limitación obviamente restringe la entrega de cuentas a solo aquellas personas competentes e instruidas con respecto a ese lenguaje en particular. Para escapar de esa limitación, las cuestiones hermenéuticas —cuestiones de significado, interpretación y comprensión-deben llegar a ser vistas de una manera independiente del lenguaje que se utilice en la entrega de las cuentas económicas ${ }^{1}$.
}

El horizonte pedagógico del saber contable contemporáneo se ha fortalecido a partir de los vínculos que hay entre los distintos saberes humanísticos y la contabilidad (Ospina \& Castaño, 2012). Se considera que la contabilidad logra su autonomía no por la especificidad de su objeto de estudio, sino por la forma en que se interrelaciona con otras disciplinas para arrogarse una

1 Traducción propia. lectura y una interpretación de la forma en que se han utilizado y proyectado los recursos de las organizaciones. Se comparte con Jorge Manuel Gil (2010, p. 113) que el conocimiento contable "concientiza respecto de la construcción de la realidad y sus causas, y no solo incide en las actitudes, sino en las visiones y cosmovisiones de los distintos actores sociales involucrados" en las dinámicas organizacionales.

De otra parte, la intercomunicación y la interdisciplinariedad permiten consolidar un pensamiento contable vinculado con experiencias científicas y cotidianas, con esquemas objetivos y miradas subjetivas. Esta combinación produce actualmente los nuevos objetos de estudio o las nuevas dinámicas sociales para pensar la naturaleza científica de la contabilidad (Gómez-Villegas, 2011). No es necesario ir más lejos para que autores como Carlos Mario Ospina y Carlos Eduardo Castaño (2012) consideren que el pensamiento contable colombiano (teoría contable) es una expresión de espíritus críticos que problematizan el pensamiento ortodoxo de la contabilidad y cuestionan desde su saber las acciones empresariales afraternales.

El diseño de currículos flexibles en Contaduría propicia el abordaje integral de los desarrollos y los problemas sociales, incluyendo los que se presentan en las empresas. Esta flexibilidad es una alternativa capaz de incidir en el entorno económico, legal, político y social de una manera ética y responsable en comparación con los currículos cuya estructura y dinámica se centra en atender las lógicas capitalistas empresariales. Ahora bien, en cuanto al papel de la contabilidad en el capitalismo, Dillard (1991, p. 10) afirma que: 
La representación de la contabilidad como una tecnología socialmente determinada no excluye o relega la dimensión social de la contabilidad, por el contrario, se reconoce explícitamente la realidad, a menudo ignorada, de que el sistema social emana de una fuente dominada por el capitalismo. La técnica es, de hecho, dominada por lo social, lo que sustancial e ideológicamente, limita las manifestaciones tecnológicas posibles. En este contexto, la contabilidad está dirigida fundamentalmente a preservar y mejorar el control de los capitalistas sobre los medios de producción ${ }^{2}$.

Sin duda, los que son capaces de diseñar estos fines a la contabilidad no son los pequeños inversores; son aquellos con capacidad de influir en la marcha de los negocios, como los grandes accionistas, los directores de empresas, las multinacionales, la banca y los fondos de inversión, entre otros. Sus acciones reflejan el tipo de pensamiento que los gobierna, pues se ajustan y corresponden a los postulados básicos del capitalismo. De manera complementaria, muchas de las acciones de los profesionales se dirigen a apoyar y movilizar las dinámicas del capitalismo. En este sentido, Luc Boltanski y Ève Chiapello (2002, p. 40) sostienen que el capitalismo necesita un espíritu que se proponga apoyarlo a ciegas, y así entonces promueve imaginarios y roles profesionales que disminuyan la crítica y fortalezcan sus redefiniciones. El capitalismo con sus ventajas y desventajas embriaga el espíritu de los profesionales que se proyectan desde las universi-

2 Traducción propia. dades. Así, las estructuras que monopolizan el mercado globalizado comprometen a los académicos y gremios que se encargan de estructurar su camino de legitimación social.

La nueva gestión empresarial que se coló con sus discursos de reconocimiento de la justicia, la equidad y la libertad, haciendo de los clientes y los trabajadores amigos aliados a sus propósitos, muestra el otro lado de la moneda que consiste en utilizar estos discursos para manipular a los actores de la empresa (Boltanski \& Chiapello, 2002, p. 581), por medio de una comunicación mistificadora, con la que se pide a los individuos que sean leales, sinceros y entusiastas, tal como se pensó que fueran los adeptos al sistema del nuevo espíritu del capitalismo, pero sometiéndolos a presiones que produjeron miedos, desconfianza y odios.

\section{Cómo entender el rol de las humanidades en un pénsum de contaduría pública}

Los currículos son un medio para facilitar que los estudiantes diseñen un camino a seguir de trabajo profesional y/o científico. Todo proyecto de formación se articula entre una pedagogía y unos saberes disciplinares que en su conjunto deben posibilitar que los estudiantes por ellos mismos comprendan los paradigmas que orientan y proyectan el saber y la profesión contable. Las profesiones como la contaduría pública se fundan en un valor fundamental: la verdad (Bermúdez-Gómez, 2002, p. 19). Así, el currículo de contaduría pública debe establecerse buscando explicar las teorías y la instrumentación (modelos, leyes, tecnologías, etc.) 
que aseguren un profesional capaz de prestar un servicio profesional objetivo y transparente. En conexión con los planteamientos de Jesse F. Dillard (1991, p.17), este considera que el científico social crítico tiene la responsabilidad de revelar la verdad social crítica, la naturaleza de la existencia y motivar a una acción social transformadora que lleve a la ciencia de la emancipación.

Si se acepta que la contaduría en Colombia es una profesión regulada, y que la "contabilidad es una asignatura multidisciplinaria con amplias bases que se volvió esencial en todas las decisiones económicas, [es necesario] incluir no solo asignaturas tradicionales, sino también una fuerte dosis de economía y ciencias de la conducta" (Manicas, 1993). Entonces, hay que aceptar que los currículos deben tener un componente en ciencias humanas y sociales (humanidades) que contribuya a formar el carácter necesario para entender la complejidad racional y moral que subyace al pensamiento y al ejercicio de la contabilidad. No es posible actuar con una norma de ética, si no se accede a una educación en ciencias sociales y humanas. Las humanidades, como señala Edward Said, han tenido cambios en sus fundamentos y por tanto, en sus aplicaciones concretas, por lo cual es necesario identificar cómo en Colombia ese cambio se debe expresar en los currículos y, específicamente, en las prácticas pedagógicas en contaduría.

Las humanidades que hacen parte de los currículos deben permitir otear que el problema de la convergencia a normas internacionales de contabilidad no puede ser una excusa para el renacimiento de nacionalismos en contadu- ría pública. Como lo señala Said (2006), los nacionalismos en su postura política son referenciados desde las ideologías que nublan la comprensión del contexto económico y social de un país. Lo anterior no quiere decir que las humanidades deben servir para procesos de formación apolítica. Por el contrario, las humanidades juegan un papel fundamental para que los estudiantes y los profesores puedan comprender los problemas y las nuevas transformaciones que pueblan las nuevas realidades en Colombia. Las humanidades no están y no deben concebirse como un ornamento para embellecer una realidad sórdida (Said, 2006, p. 63). Se considera que las humanidades que hacen parte de los programas de estudio en contaduría pública deben estar atentas a los problemas sociales y las perspectivas de vida que se dejan entrever en los estudiantes y a las nuevas expresiones de interacción colectiva.

¿Qué es lo propio que se debe esperar de unas asignaturas de humanidades en un programa de estudio de contaduría pública? En principio, por medio de ellas es posible entender que los paradigmas y las epistemologías, tal como lo señalan Michel Foucault, Friedrich Nietzsche, Gilles Deleuze, modulan las subjetividades en todas partes del mundo. La tarea fundamental de las humanidades es provocar el deseo y la fuerza para poner en duda las lecturas y las representaciones que se presentan desde todas las asignaturas. Así lo señala Edward Said (2006, p. 65):

\footnotetext{
El humanismo, en cierta medida, es una oposición a las idées reçues, y opone resistencia a todo tipo de estereotipos y len-
} 
guajes poco reflexivos (...) lejos de que el quehacer humanístico venga determinado por circunstancias socioeconómicas, lo que reviste el máximo interés es la dialéctica de los opuestos, del antagonismo entre esas circunstancias y el humanista individual, y no la conformidad ni la identidad.

Las humanidades justifican su presencia en los programas de contaduría pública porque desde ellas se puede: primero, descifrar y proyectar caminos de libertad para pensar algunos de los diversos problemas colombianos que facilitan o imposibilitan el desarrollo de la disciplina y del quehacer contable; segundo, porque permiten poner en duda las ideas que subyacen al conocimiento contable, máxime cuando este no ha sido lo suficientemente problematizado por los "contadores profesionales" específicamente en lo concerniente a las teorías y menos aún en los modelos que se utilizan para producir, procesar e interpretar la información contable financiera. Las ciencias humanas forjan caminos para enfrentar la racionalidad instrumental (Horkheimer, 2002) que, poco a poco, ha ido deshaciéndose de la dignidad de las personas trabajadoras; el mito del mercado competitivo infinito encuentra en la dignidad humana un obstáculo para su repotenciación devoradora. La formación humanística sirve para que los estudiantes puedan ver cómo las contradicciones, las antinomias de su tiempo, amenazan con la posibilidad de perder la esperanza en una vida digna.

La educación universitaria no puede quedarse centrada en un proceso de asimilación de información de culturas eurocéntricas y esta- dounidenses que impiden desconocer las rupturas y desarrollo existente en las tradiciones locales. La formación humanística debe lograr que los estudiantes apropien la tesis de que la "sociedad no puede existir independientemente de la actividad humana (...) que ella solo está presente en la acción humana y la acción humana siempre expresa y utiliza una u otra forma social (...). La realidad social es, entonces, subjetivamente creada y objetivamente real" (Chua, 1986, citado por Manicas 1993, p. 157).

Así, los estudiantes de contaduría pública podrán percibirse como sujetos dignos de problematizar y comprender algunas de las expresiones sociales del momento colombiano: la oposición a las explotaciones de la riqueza mineral, el reclamo por el crecimiento de los sin techo, las acciones solidarias por la tragedia que viven los desplazados, el desarrollo de proyectos que reconocen a los afrodescendientes y a las comunidades LGTBI, etc.

Las humanidades proveen las herramientas cognitivo interpretativas para que los programas de estudio velen por que los estudiantes puedan desujetarse de los pilares ideológicos que se centran, como diría Said, en el "universalismo estereotipado de los imperios". Un currículo que valore las humanidades debe preparar a sus estudiantes para que no se aten a las hegemonías conductuales que se derivan de la política de financiarización de los organismos reguladores del capital. Por lo tanto, "en lugar de enfatizar una lógica unitaria de eficiencia transicional, [los estudiantes entenderán que] la contabilidad debe usar un análisis causal en un contexto histórico" (Montagna, 1986, p. 129). Un currículo no se legitima solo ante 
el mercado empresarial globalizado y ante los organismos que rigen el ultraliberalismo económico de nuestros tiempos. ¿Acaso los educadores no deben hacer un alto en el camino para pensar por qué una sociedad como la nuestra, tan regulada en términos de nuestra profesión, ha permitido la aparición de muchas prácticas fraudulentas y corrosivas que ponen en entredicho la valoración ética de la contaduría pública?

Se comparte la tesis de Stella Maldonado (2002), que sostiene que:

\begin{abstract}
...Contabilidad más que una técnica es, como campo del conocimiento, una institución eminentemente humana que responde a situaciones particulares de tiempo y lugar en cuanto a los principios morales que la determinan, y que no puede responder en su accionar a una ética universal puesto que esta depende del deber ser de cada individuo según la manera como asuma estos principios morales, que dependen a su vez de situaciones particulares, necesariamente compartidas por todos, que la hacen viable dentro de un grupo social específico.
\end{abstract}

No se sabe claramente, por qué razones los académicos no se permiten de manera más constante un alto en el camino para pensar lo que se hace frente a lo que se debe hacer. Cómo entender que gran parte de las regulaciones internacionales y el imaginario managerial ${ }^{3}$ que orienta el accionar organizacional de una u otra forma han promovido que la profesión contable

3 Este concepto se puede ampliar en Luis Enrique Alonso y Carlos Jesús Fernández-Rodríguez (2013). se inserte en una ideología que se ha despreocupado por los altos índices mundiales de pobreza y por las consecuencias ambientales del proceder industrializado. En efecto, según el Informe sobre desarrollo humano 2014. Sostener el progreso humano: reducir vulnerabilidades $y$ construir resiliencia, del Programa de Naciones Unidas para el Desarrollo, PNUD (2014), los indicadores de pobreza multidimensional señalan que 1.500 millones de personas viven en esta condición; y que 1.200 millones viven con menos de 1,25 dólares diarios, a causa de la crisis mundial.

Si bien la formación humanística no garantiza el respeto absoluto de la dignidad humana, tal como lo expresa George Steiner (1992), ni la efectiva aplicación de las acciones encaminadas a la conservación del planeta (Rueda, 2002), ésta posibilita caminos alternativos para el desarrollo y progreso humanos; esta formación se fortalece desde una práctica pedagógica en relación directa con los problemas sociales y económicos que nos afectan, a partir de lo que observan y/o dejan ver los estudiantes con respecto a su propio contexto y proyecto de vida profesional. Lo anterior facilita que el futuro contador público pueda otear caminos para defender las identidades históricas y culturales que pueblan nuestra nación y que se resisten a ser reducidas a una única tradición, a una única raza y una única religión. Un contador público no puede sentirse extranjero frente a las valoraciones y las subvaloraciones del patrimonio cultural de nuestras etnias ni de nuestras riquezas naturales.

Actuar éticamente en la perspectiva de los desarrollos más sublimes de las humanidades 
implica reconocer que todos los pregrados deben advertir sobre la destructividad que subyace en todos los proyectos que se enuncian a sí mismos como civilizatorios. No se puede desconocer que el alma formativa y reconstructiva de un programa, se consolida si al momento de elaborar un PEP (Proyecto Educativo de un Programa) se precisa que las humanidades constituyen uno de los medios pedagógicos que facilitan entender e internalizar el porqué y el cómo, el otro debe ser objeto de respeto.

Es indudable que si se leen las misiones y las certificaciones de muchos de los programas académicos que ofrecen contaduría pública, se puede creer que todo anda muy bien, y con mayor razón, se puede pensar que se han logrado grandes orientaciones para la formación contable. Pero en contravía del papel, hay realidades que señalan que las universidades y sus proyectos educativos se han quedado cortos para enfrentar el presente de las nuevas hordas bárbaras que, según Alessandro Baricco, se han ido rindiendo al talento superficial, frívolo que no cree en el valor de la poesía ni en las visiones humanísticas (2013, pp. 32-33).

Citemos un apartado de la novela No es país para viejos, de Cormac McCarthy, que retoma con preciosa pertinencia Baricco en su obra:

Era de trato fácil. Me llamaba sheriff. Pero yo no sabía qué decirle. ¿Qué le dices a un hombre que reconoce no tener alma? ¿Qué sentido tiene decirle nada? Pensé mucho en ello... Pero él no era nada comparado con lo que estaba por venir" (2013, p. 33).
Se considera necesario avivar la emergencia de proyectos formativos universitarios que problematicen el academicismo que acepta la aparente objetividad del mercado y la gestión académica directamente relacionada con la satisfacción de estándares que soportan el orden instaurado por la civilización instrumental contemporánea.

Es importante entonces resistirse a que las lógicas del mercado y los presupuestos de la empresa competitiva se impongan como un referente único para el diseño de los programas de estudio. ¿Cómo pedir un profesional comprometido con una praxis contable, si nuestra comunidad académica no ha decantado los mecanismos para explicar las bases morales y científicas necesarias para transformar los imaginarios manageriales que ven en la contaduría un mero oficio de cálculo que se legitima en sus aportes al desarrollo del mercado ultraliberal contemporáneo? (Dufour, 2007).

Es hora de exhortar a pensar que no se es presa de una sociedad autista y trivializadora de la vida. Se sabe que las humanidades no garantizan per se la aparición de un sujeto ético, pero también se sabe que una buena formación se puede anteponer a la profesionalización normalizadora y afraternal. Surge así el compromiso con la creación de un espacio de resistencia frente a las emociones enceguecedoras que se pliegan al hiperconsumo.

El hecho de que las asignaturas de ciencias sociales y humanas se hayan constituido para muchos estudiantes en "asignaturas de relleno" en los pregrados y los posgrados de las llamadas ciencias naturales y exactas, ingenierías y ciencias de la administración en las universi- 
dades colombianas, se puede deber a que la gran mayoría de profesores y estudiantes cada vez más son apresados por sofisticados y poderosos mecanismos que facilitan la deshumanización de los seres humanos. El problema de nuestra educación y de nuestra formación no solo se debe a problemas de práctica pedagógica, sino también a que las personas no han sido capaces de entender su sujeción a una red de mecanismos que los preparan para ser insensibles frente al sufrimiento de los otros. En el campo empresarial esta insensibilidad se expresa en el planteamiento que presenta Héctor L. Bermúdez-Restrepo refiriéndose al trabajo de Vivianne Châtel sobre la inexistencia social: "No se puede aceptar un lenguaje que nombra al ser humano como a una cosa, eso sería contribuir a su degradación. Así entonces, urge denunciar el vocabulario utilizado por los funcionarios públicos y los ejecutivos de las empresas que nombran los asuntos humanos con un discurso que tendría que resultar irritante, por ejemplo, el management nombra los problemas humanos con un discurso perverso. Las empresas consideran a los trabajadores como recursos, es decir, como utensilios, como herramientas" (Bermúdez-Restrepo, 2010, p. 254).

En esta misma dirección, para pensar autónomamente la contabilidad como un saber que soporta tecnologías contables, se debe asegurar un proceso de formación individual que facilite desestructurar los imaginarios y las prácticas afraternales del sistema mundo ultraliberal que procura que todo lo humano se mueva bajo los ejes del precio y el costo competitivo. Se cree que la "cordura debe buscarse precisamente en la capacidad que tenemos para juzgar nuestra propia conducta, en el proceso de reflexión que ejercemos cuando pensamos nuestros actos y los actos de los otros...". La cordura en nuestro ejercicio profesional solo puede materializarse con el propósito de formar para impedir el crecimiento de la moral indolora que rige la ley del más fuerte.

A modo de ejemplo se señalan algunas consideraciones tomadas del pensamiento de Martha Nussbaum (2012), sobre qué exige, en un contexto crítico, el mundo global a la universidad.

- La formación para la ciudadanía y para la vida.

- El pensamiento crítico.

- El análisis argumentativo.

- La cultura de lo público y el debate original.

- El conocimiento del mundo: historia universal, las principales religiones del mundo, las tradiciones étnicas, el sistema económico mundial.

- El entrenamiento de la imaginación: todos tenemos la capacidad de imaginar el punto de vista de otras personas, pero realmente no la desarrollamos. Solo la usamos cuando queremos algo de la otra persona.

- No se puede aprender de todo en un pregrado, pero teniendo un conocimiento básico de historia mundial, de religiones del mundo, del sistema económico internacional, se estará preparado para comprender, después todo, aquello que la vida exige.

Es preciso reconocer que se asiste a una sociedad colombiana marcada con escandalosos índices de corrupción, violencia, analfabetismo, con prácticas que favorecen el atajismo, pero 
también a una sociedad abierta, en la que se ha criticado la forma en que los gobiernos y los empresarios han ocultado su información. Así las cosas, la educación contable debe entender que la universidad está para potenciar las libertades y la independencia de los sujetos. Si se piensa que la tarea de la educación superior en Colombia es preparar a los profesionales para que logren enfrentar la complejidad de nuestro presente, en vez de incidir críticamente en su transformación, eso sería renunciar a la esencia del ethos universitario clásico, por medio del cual se exhorta a la construcción de un bienestar para todos y a edificar un futuro promisorio y de progreso para la sociedad. Cuando las humanidades no se potencian en los programas de estudio, se corre el riesgo de que estas sean usadas como un simple maquillaje del diseño curricular, o peor aún, como medios de persuasión psicológica para favorecer la obediencia ciega a una racionalidad instrumental que se opone al desarrollo crítico de los saberes. Para terminar, se señalan unas palabras del maestro Fernando Cruz-Kronfly (2012) en el V Seminario Internacional Nuevo Pensamiento Administrativo:

Occidente es hoy una lastimosa promesa incumplida. El imaginario del progreso moral y material de la humanidad, que en otro tiempo llegó a ser un axioma indiscutible, hoy produce risa. Es necesario descender al realismo para entender nuestro tiempo, nunca instalarse en el pesimismo. Para esto son este tipo de escenarios académicos. Que no nos echen más cuentos, que no nos digan más que la industria y la economía ansiosa lanzada a la competitividad y la demanda delirante son la salida. El mundo debe poner fin a la voracidad siniestra del sector financiero. Ya no más. Hay que detenerse a pensar. Hay que parar en seco las ideologías manageriales, y el escenario de esta tarea crítica son las universidades públicas e incluso las privadas que se quieran sumar. No más fórmulas y recetas inocentes, no más gerentes mundiales avivatos, no más mundos económicos gobernados por idiotas morales incapaces de formularse ellos mismos la pregunta por el bien y por el mal respecto de lo que hacen y sus consecuencias. En el mundo hipermoderno de los negocios, la pregunta ética no solo se ha desvanecido sino que se ha tornado incómoda, impertinente, molesta, subversiva.

\section{Conclusiones}

La globalización económica y social muestra dos caras en términos de los procesos educativos y formativos para los profesionales, por un lado, sus estrategias de dominación canalizadas mediante los órganos multinacionales, demandan una educación funcional e instruccional, que, puesta en el campo contable, urge de profesionales bien educados pero no formados, con ímpetu y fuerza para engrosar los engranajes del sistema del capital sin mayores pretensiones de cuestionamiento alguno; y por el otro, al son de la libertad de tránsito cualquier individuo tiene en su voluntad la decisión de formarse, de complementar su educación con una sensibilidad cultural, social y política que le permita evaluar críticamente las contradiccio- 
nes y complejidades de la sociedad. En el campo contable, esta formación va a conducir al profesional a estar consciente del rol que juega en un escenario inequitativo y afraternal, siendo capaz de reinterpretar la vida organizacional a la luz del valor por la dignidad humana, el medio ambiente y el bienestar colectivo.

A lo largo de la historia, las humanidades (ciencias sociales y humanas) han cumplido un papel fundamental en la explicación y comprensión de los fenómenos sociales; en esa medida, su vinculación a otros saberes no puede prescindirse; así, la profesión contable y la disciplina de la contabilidad, de manera categórica, requieren desarrollarse y problematizarse al lado de estas ciencias. La contaduría pública, sin lugar a dudas, puede ser una profesión estratégica para el desarrollo de las organizaciones produciendo información justa, transparente, con sentido social, guardiana del capital social que posibilita el crecimiento económico, la legitimidad de las instituciones y la buena calidad de vida de las personas.

Asimismo, en su tarea de mejoramiento continuo con los más altos estándares de calidad, los programas de contaduría pública del país pueden construir nuevas miradas sobre la educación y la formación de profesionales. Lo anterior de la mano de la resignificación de las ciencias sociales y humanas en la explicación y comprensión de la praxis contable, mediante la cual se leen las "fotografías" del cuerpo organizacional. Si bien atiende los conceptos básicos de la racionalidad económica, la estructura de los programas no debe alejarse de marcos referenciales como la historia, la filosofía, la política, la sociología y la antropología, entre otros, que con seguridad fortalecen el conocimiento y la pedagogía que dignifican la profesión contable.

Por último, el reto de formar contadores públicos capaces de reinventar la contaduría pública involucra a muchos actores de la comunidad contable, entre ellos, los docentes, los investigadores, los directivos de programas académicos y, en alguna medida, a los profesionales en ejercicio. Todo pasa por desarrollar la capacidad de leer crítica e interpretativamente el conjunto de prácticas contables, como las educativas, las profesionales y las institucionales, enmarcadas todas en escenarios económicos rodeados de relaciones de poder. Urge entonces seguir adelante con estudios sobre la educación y la formación de contadores públicos. Esta embrionaria reflexión necesita mayores debates que retroalimenten los argumentos aquí expuestos, con análisis interdisciplinarios que conecten el saber contable con los nuevos paradigmas de la información y la revelación transparente adecuada al desarrollo social contemporáneo.

\section{Referencias}

Alonso-Benito, Luis Enrique \& Fernández-Rodríguez, Carlos Jesús (2013). Los discursos del presente. Un análisis de los imaginarios sociales contemporáneos. Madrid: Siglo XXI Editores.

Arrington, Edward \& Francis, Jere R. (1993). Giving Economic Accounts: Accounting as Cultural Practice. Accounting, Organizations and Society, 18 (2-3) 107-124. 
Baricco, Alessandro (2008). Los bárbaros. Ensayo sobre la mutación. Barcelona: Anagrama. Bermúdez-Gómez, Hernando (2002). Crítica del sistema ético-legal de la contaduría pública colombiana. Cuadernos de Contabilidad, 3 (16), 15-65. Disponible en: http:// cuadernosdecontabilidad.javeriana.edu.co/ vol3_n_16/vol3_16_2.pdf

Bermúdez-Restrepo, Héctor L. (2010). Pensar la inexistencia social. Reflexiones acerca de una idea de Vivianne Châtel. Revista Teuken Bidikay, 1, 249-261.

Boltanski, Luc \& Chiapello, Ève (2002). El nuevo espíritu del capitalismo. Madrid: Ediciones Akal S.A.

Cardona-Arteaga, John \& Zapata-Monsalve, Miguel Ángel (2006). Educación contable: antecedente, actualidad y prospectiva. Medellín: Universidad de Antioquia.

Chua, Wai Fong (1986). Radical Developments in Accounting Thought. The Accounting Review, 61 (4), 601-632.

Cruz-Kronfly, Fernando (2012). ¿Reconocimiento \& desarrollo humano en las organizaciones? Conferencia presentada en el IV Seminario Internacional Nuevo Pensamiento Administrativo. Universidad del Valle. Cali, Colombia.

Dillard, Jesse F. (1991). Accounting as a Critical Social Science. Accounting, Auditing \& Accountability Journal, 4 (1), 8-28.

Dufour, Dany-Robert (2007). El arte de reducir cabezas. Sobre la nueva servidumbre del hombre liberado en la era del capitalismo total. Buenos Aires: Paidós.

Gil, Jorge Manuel (2010). Retos de la contabilidad frente a la globalización: Perspectivas de la teoría y la investigación contable. En Perspectivas críticas de la contabilidad contemporánea, 101-126. Cali: Universidad del Valle, Pontificia Universidad Javeriana Cali. Gómez-Villegas, Mauricio (2007). Las insuficiencias disciplinares de los Estándares Internacionales de Educación IES - para contadores profesionales. Revista Latinoamericana de Pensamiento, Teoría e Investigación Contable Lúmina, 8, 24-42. Disponible en: http://revistalumina.mex. tl/884260_Lumina-8.html, https://app.box. com/shared/lzue2kksn1

Gómez-Villegas, Mauricio (2011). Pensando los fundamentos de la Contabilidad como disciplina contable. Revista Lúmina, 12, 120 150. Disponible en: http://www.umanizales. edu.co/publicaciones/campos/economicas/ lumina/recursos/12/7_pensando.pdf

Gracia, Édgar (1996). A propósito del contexto económico y los escenarios I. Revista Lúmina, 1, 53-59. Disponible en: https://app.box. com/shared/hg3bxi3z5hu95373p2lc

Gracia, Édgar (2000). Situación actual de la investigación contable en Colombia. Ponencia, IX Foro Internacional Nuevas Perspectivas del Conocimiento Contable. Bogotá.

Gracia, Édgar (2002). El estado actual de la educación contable en Colombia. En Olver Quijano-Valencia, Édgar Gracia-López, Guillermo León Martínez-Pino, Efrén Danilo Ariza-Buenaventura \& William Rojas-Rojas. Del hacer al saber. Realidades y perspectivas de la educación contable en Colombia. Popayán: Universidad del Cauca.

Horkheimer, Max (2002). Crítica de la razón instrumental. Madrid: Editorial Trotta. 
Maldonado, Stella (2002). La contabilidad, un área de conocimiento de alto contenido ético y cultural. Cuadernos de Contabilidad, 13 (16), 121-140. Disponible en: http:// cuadernosdecontabilidad.javeriana.edu.co/ vol3_n_16/vol3_16_8.pdf

Manicas, Peter (1993). Accounting as a Human Science. Accounting, Organization and Society, 18 (2-3), 147-161.

Martín-Barbero, Jesús (2002). La crisis de las profesiones en la sociedad del conocimiento. Revista Nómadas, 16, 177-182. Disponible en: http://dialnet.unirioja.es/servlet/articul o;jsessionid=49B37A2C32882F2D583678 D290F56E57.dialnet02?codigo $=3991411$

Martínez-Pino, Guillermo (2002). El rediseño curricular contable: entre lo profesional y lo disciplinar. En Olver Quijano-Valencia, Édgar Gracia-López, Guillermo León Martínez-Pino, Efrén Danilo Ariza-Buenaventura \& William Rojas-Rojas. Del hacer al saber. Realidades y perspectivas de la educación contable en Colombia. Popayán: Universidad del Cauca. Disponible en: http://ciberconta. unizar.es/leccion/rediseno/rediseno.pdf Martínez-Pino, Guillermo (2008). La educación contable: encrucijada de una formación monodisciplinaria en un entorno complejo e incierto. Popayán: Editorial Universidad del Cauca, serie Estudios Sociales.

McCarthy, Cormac (2006). No es país para viejos. Barcelona: Random House Mondadori. Montagna, Paul (1986). Accounting Rationality and Financial Legitimation. Theory and Society, 15 (1), 103-138.

Nussbaum, Martha C. (2012). Crear capacidades: propuesta para el desarrollo humano.
Albino Santos-Mosquera (trad.). Barcelona: Paidós.

Ospina, Carlos Mario (2006). Las tramas de la contabilidad. Trazos para quienes empiezan su formación en contaduría pública. Contaduría, Universidad de Antioquia, 48, 155-186.

Ospina, Carlos Mario \& Castaño, Carlos Eduardo (2012). El campo de la teoría contable: distinciones centrales para subrayar el papel de la Universidad de Antioquia en el contexto colombiano. En Marco Antonio Machado-Rivera (ed.). Huellas y devenir contable: construyendo las rutas del pensamiento contable, 222-275. Medellín: Universidad de Antioquia.

Programa de Naciones Unidas para el Desarrollo, PNUD (2014). Informe sobre desarrollo humano 2014. Sostener el progreso humano: reducir vulnerabilidades y construir resiliencia. Nueva York: Programa de Naciones Unidas para el Desarrollo, PNUD. Disponible en: http://hdr.undp.org/sites/ default/files/hdr14-report-es.pdf

Quiceno, Humberto (2001). Formación y educación. Ponencia publicada en Universidad del Valle (ed.), 15 Congreso Nacional de Estudiantes de Contaduría Púbica, Memorias. Cali.

Quijano-Valencia, Olver (2002). Nuevos tiempos, nuevas competencias. De las monocompetencias a la policognición. En Olver Quijano-Valencia, Édgar Gracia-López, Guillermo León Martínez-Pino, Efrén Danilo Ariza-Buenaventura \& William Rojas-Rojas. Del hacer al saber. Realidades y perspectivas de la educación contable en Colombia. Popayán: Universidad del Cauca. 
Rojas-Rojas, William (2002). La educación contable en Colombia 1960-2000: al servicio de la afraternidad económica moderna. En Olver Quijano-Valencia, Édgar Gracia-López, Guillermo León Martínez-Pino, Efrén Danilo ArizaBuenaventura \& William Rojas-Rojas. Del hacer al saber. Realidades y perspectivas de la educación contable en Colombia. Popayán: Universidad del Cauca. Disponible en: http://bibliotecadigital.univalle.edu.co/ handle/10893/2082

Rojas-Rojas, William (2009). Contribución de las ciencias sociales y humanas a la formación del contador público. En Irrupciones significativas para pensar la contabilidad. Cali: Universidad del Valle. Disponible en: http://administracion. univalle.edu.co/Comunidad/Memorias/ evento1/archivos/Contribucion\%20de $\% 20$ las\%20ciencias\%20sociales\%20y\%20 humanas\%20a\%20la\%20formacion $\% 20$ del\%20contador\%20publico.pdf

Rueda, Gabriel (2002). Desarrollo alternativo y contabilidad: una aproximación. Revista Legis del Contador, 6, 11-129.

Rueda-Delgado, Gabriel; Pinzón-Pinto, Jorge Emiro \& Patiño-Jacinto, Ruth Alejandra
(2013). Los currículos de los programas académicos de contaduría pública, tras la enseñanza de lo internacional y la globalización en la contabilidad: necesidades de ajuste más allá de respuestas técnicas. Cuadernos de Contabilidad, 14 (35), 639-667. Disponible en: http://revistas.javeriana.edu.co/index.php/cuacont/article/view/7110/5632 Said, Edward (2006). Humanismo y crítica democrática. Ricardo García-Pérez (trad.). Barcelona: Debate.

Steiner, George (1992). En el castillo de Barba Azul. Aproximación a un nuevo concepto de cultura. Madrid: Gedisa.

- Fecha de recepción: 2 de octubre de 2014

- Fecha de aceptación: 8 de abril de 2015

- Disponible en línea: 30 de abril de 2015

\begin{tabular}{|l|}
\hline Para citar este artículo \\
Rojas-Rojas, William \& Giraldo-Garcés, Gre- \\
gorio A. (2015). Humanidades \& forma- \\
ción contable: una relación necesaria \\
para otear una reorientación de la pro- \\
fesión contable. Cuadernos de Contabi- \\
lidad, 16 (40), 261-276. http://dx.doi. \\
org/10.11144/Javeriana.cc16-40.hfcr
\end{tabular}

